${ }^{3}$ Department of Chemical Pathology, Ahmadu Bello University, Zaria, Nigeria

${ }^{4}$ Department of Medicine, Ahmadu Bello University, Zaria, Nigeria

\title{
Hypergonadotropic hypogonadism in Nigerian men with type 2 diabetes mellitus
}

\section{ABSTRACT}

Background. Studies have reported a higher prevalence of hypogonadism in men with type 2 diabetes mellitus (T2DM) than non-diabetic men. The pattern of hypogonadism in men with T2DM using gonadotropin-releasing hormone $(\mathrm{GnRH})$ stimulation test in Sub-Saharan Africa is unknown.

Objective. This study was conducted to determine the prevalence and pattern of hypogonadism in Nigerian men with T2DM.

Methods. A cross-sectional study involving 358 men with T2DM and 179 non-diabetic men as controls. Androgen Deficiency in the Ageing Male (ADAM) questionnaire was administered. Luteinizing hormone (LH) and follicle-stimulating hormone (FSH) both at 0 hours and 4 hours after subcutaneous buserelin injection, fasting total testosterone (TT), fasting plasma glucose and glycated haemoglobin were measured. Ninety-nine men with T2DM selected by randomization using a computer underwent GnRH stimulation test, with subcutaneous injection of 100 micrograms of buserelin.

Results. The mean TT of T2DM men was significantly lower compared to the controls $(8.79 \pm 3.35 \mathrm{nmol} / \mathrm{L}$ vs $15.41 \pm 3.79 \mathrm{nmol} / \mathrm{L}, \mathrm{p}<0.001)$. The prevalence of

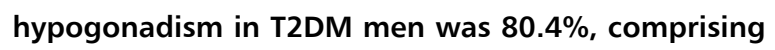
$38.5 \%$ of severe hypogonadism and $41.9 \%$ mild hypogonadism. The mean LH and FSH levels were significantly

Address for correspondence:

Ezekiel Musa

Department of Internal Medicine,

Kaduna State University, Nigeria

e-mail: ezemusa2000@gmail.com

Clinical Diabetology 2021, 10, 1: 129-137

DOI: $10.5603 /$ DK.a2021.0002

Received: 23.08 .2020

Accepted: 28.12.2020 higher in T2DM men than the controls $(9.62 \pm 6.82 \mathrm{IU} / \mathrm{L}$ vs $8.24 \pm 5.91 \mathrm{IU} / \mathrm{L}, \mathrm{p}=0.022$ and $8.50 \pm 8.17 \mathrm{IU} / \mathrm{L}$ vs $5.17 \pm 3.89 \mathrm{IU} / \mathrm{L}, \mathrm{p}<0.001$ respectively). There was a statistically significant exaggerated response in mean $( \pm$ SD) LH and FSH levels at 4 hours after buserelin injection compared to the 0 -hour levels $(58.58 \pm 40.72$ $\mathrm{IU} / \mathrm{L}$ vs $8.38 \pm 6.10 \mathrm{IU} / \mathrm{L}, \mathrm{p}<0.001$ and $23.03 \pm 18.02$ $\mathrm{IU} / \mathrm{L}$ vs $8.41 \pm 7.45 \mathrm{IU} / \mathrm{L}, \mathrm{p}<0.001$ respectively) in men with T2DM who had GnRH stimulation tests.

Conclusion. This study shows that the prevalence of hypogonadism in men with T2DM is significantly higher than in non-diabetic men with mild hypogonadism accounting for most cases. Hypergonadotropic hypogonadism occurs more frequently in men with T2DM in Nigeria. (Clin Diabetol 2021; 10, 1: 129-137)

Key words: hypergonadotropic hypogonadism, hypogonadism, type 2 diabetes mellitus, GnRH stimulation, total testosterone

\section{Introduction}

Diabetes mellitus is a major non-communicable disease encountered worldwide with a more significant burden in developing countries. International Diabetes Federation reported that $80 \%$ of people affected by diabetes mellitus (DM) globally are from low and middle-income countries [1]. Sub-Saharan Africa and other African countries are experiencing a rise in the prevalence of diabetes due to increasing life expectancy of the population, urbanization and adoption of the western lifestyle $[2,3]$. Several cross-sectional studies have shown an increasing trend in DM prevalence in Nigeria [4-6].

Hypogonadism is a clinical syndrome of symptoms, with or without signs, in conjunction with biochemical 
evidence of testosterone deficiency $[7,8]$. It is associated with several metabolic consequences, including T2DM, insulin resistance, metabolic syndrome, osteoporosis and carotid atherosclerosis [9-12].

Several studies have reported hypogonadism to be associated with T2DM [13-17]. In cross-sectional studies conducted in Nigeria, Ogbera et al. reported the prevalence of hypogonadism to be $36 \%$ among type 2 diabetic men attending Gbagada General Hospital Lagos. Meanwhile, Onung et al. and Ugwu et al. reported the prevalence of hypogonadism to be $38.9 \%$ and $52.5 \%$ in men with T2DM in Lagos and lle-Ife, respectively [15-17]. In South Africa, Kemp et al reported the prevalence of androgen deficiency symptoms to be $94.7 \%$ among male diabetics aged 50 years and above [18]. The mechanisms underpinning hypogonadism in T2DM have been postulated to include obesity, adipocytokine mediated inhibition of gonadotropins and leydig cell dysfunction, testicular steroidogenesis inhibition, hyperoestrogenaemia due to exaggerated aromatase activity and decreased sex hormone-binding globulin levels [7, 10, 13, 19].

There is under-diagnosis of hypogonadism in the general population, possibly due to non-specificity of symptoms, shame and embarrassment in talking about sexual matters and inadequate information about the condition among some health care workers [7]. Among these many symptoms of hypogonadism are reduced/ loss of libido, reduced quality and frequency of erections, fatigue, decreased physical strength and endurance, change in mood with depression and irritability, hot flushes and sweats, central adiposity, sarcopenia and gynaecomastia [7].

Several studies have reported that hypogonadotropic hypogonadism accounts for the majority of the cases of hypogonadism in T2DM [16, 20, 21]. However, primary hypogonadism (hypergonadotropic hypogonadism) has been reported with higher frequency in people with diabetes compared to non-diabetics [22].

Specific specialized tests are useful in evaluating borderline gonadotropin ( $\mathrm{LH}$ and FSH) levels in the setting of hypogonadism. They include gonadotropinreleasing hormone $(\mathrm{GnRH})$ stimulation test, clomiphene stimulation test, and human chorionic gonadotropin (hCG) stimulation test [23]. Gonadotropin-releasing hormone stimulation test involves an intravenous injection of $100 \mu \mathrm{g}$ of $\mathrm{GnRH}$ to cause a rise in serum $\mathrm{LH}$ levels by 3-6-fold and FSH between $20 \%$ and $50 \%$ after 30 minutes in a normal pituitary response. Alternatively, pituitary stimulation with $\mathrm{GnRH}$ agonists such as buserelin has been suggested to have a better discriminating effect between testicular and pituitary disorders [24]. In GnRH agonists (Buserelin) stimulation test, $100 \mu \mathrm{g}$ of buserelin is administered subcutaneously. Blood samples are collected at 0 - and 4-hours post-injection for analysing LH and FSH levels [24]. Primary testicular failure causes an exaggeration in $\mathrm{LH}$ and FSH peak levels while hypothalamic or pituitary disorders show a decreased or normal response [23].

Currently, few studies have reported on the pattern of hypogonadism in men with T2DM in Sub-Saharan Africa using basal gonadotropins (LH and FSH) [16, 22]. There is currently no available data reporting the pattern of hypogonadism in men with type 2 diabetes mellitus using a GnRH stimulation test in Sub-Saharan Africa, particularly of importance in those with borderline gonadotropin levels. Furthermore, our study had the largest sample size among other studies that have earlier reported on hypogonadism or low testosterone in men with T2DM in Sub-Saharan Africa [15-18, 22, 25]. This study assessed the prevalence and pattern of hypogonadism in Nigerian Men with T2DM.

\section{Material and methods}

This study was a cross-sectional comparative study involving 358 men with T2DM and 179 healthy nondiabetic men who served as controls. The study was conducted at the Endocrine clinic of Ahmadu Bello University Teaching Hospital (ABUTH), Zaria, Nigeria. A cohort of 99 men was selected from the pool of 358 type 2 diabetic subjects by randomization using a computer for the $\mathrm{GnRH}$ stimulation test. Ethical clearance for the study was obtained from ABUTH ethical committee (ABUTHZ/HREC/NP18/2015), and participants gave written informed consent.

Exclusion criteria were refusal to participate in the study, male patients on previous or present treatment of hypogonadism with testosterone and anti-androgen or related drugs, patients with chronic liver disease, chronic kidney disease, panhypopituitarism and HIV, patients on admission, patients with type 1 diabetes, age less than 21 years and patients with suspected prostate or testicular cancer.

A structured questionnaire was administered to study participants to obtain information on biodata, medical history, smoking history, alcohol history and medication. The Androgen Deficiency in the Ageing Male (ADAM) questionnaire was also administered to obtain information about features of hypogonadism [26].

Fasting samples $(10 \mathrm{~mL})$ were collected in the morning between 8:00 $\mathrm{AM}$ and 10:00 $\mathrm{AM}$ into plain tubes by venipuncture of an antecubital vein. The sera were collected after centrifugation into sample bottles and frozen at $-20{ }^{\circ} \mathrm{C}$. These were used for the analysis of total testosterone, $\mathrm{LH}, \mathrm{FSH}$, fasting plasma glucose. Additional $4 \mathrm{ml}$ of blood was collected into EDTA bottle for $\mathrm{HbA}_{1 \mathrm{c}}$ assay. 
To perform a GnRH stimulation test, GnRH agonist (buserelin) was injected subcutaneously at a dose of 100 micrograms using an insulin syringe. Blood sampling at 0 and 4 hours for $\mathrm{LH}$ and FSH, in 99 selected men with T2DM was performed. Buserelin was available as injection suprefact in $1 \mathrm{mg} / 1 \mathrm{~mL}(5.5 \mathrm{~mL} / \mathrm{vial})$, manufactured by Sanofi-Aventis Deutschland $\mathrm{GmbH}$, Industriepark Hoschst, 65926 Frankfurt am Main, Germany.

Serum total testosterone was measured by an enzyme immunoassay technique using Testosterone AccuBind ELISA kits from Monobind Inc, CA, USA, serum $\mathrm{LH}$ and FSH were measured by an enzyme immunoassay technique using LH and FSH AccuBind ELISA kits respectively from Monobind Inc, CA, USA. Glycated haemoglobin was measured using the Clover A1C TM self/test cartridge (South Korea). Hypogonadism was diagnosed using total testosterone levels $<8 \mathrm{nmol} / \mathrm{L}$ with or without symptoms or total testosterone levels of 8-12 nmol/L with the presence of symptoms [27].

Data were analyzed using Statistical Package for Social Sciences (SPSS) version 21 after validation to detect and correct errors before entry into SPSS. Descriptive analysis of data was performed for means and standard deviations, frequencies, and percentages. Quantitative variables such as age, FPG, $\mathrm{HbA}_{1 c^{\prime}}$ testosterone levels, LH and FSH levels were presented as means and standard deviations. Student's t-test was used to determine the difference in FPG, $\mathrm{HbA}_{1 \mathrm{c}^{\prime}}$ testosterone levels, LH and FSH levels between type 2 diabetic men and controls. Correlations between hormones and obesity and glycaemia in men with T2DM was assessed using univariate linear regression. $P$ values $<0.05$ were considered statistically significant.

\section{Results}

Socio-demographic characteristics of the men with type 2 diabetes mellitus and controls

The primary study population comprised of 358 men with T2DM and 179 controls who were recruited following fulfilment of the inclusion criteria. The participants' socio-demographic characteristics are summarized in Table 1. The mean age (SD) of the men with T2DM was $46.34 \pm 5.66$ years, while that of the controls was 44.09 \pm 12.39 years. There was no statistically significant difference between the mean age of men with T2DM and the controls ( $p=0.570$ ). Majority of both men with T2DM (98.9\%) and controls (79.9\%) were married (Table 1$)$.

\section{Clinical characteristics of men with type 2 diabetes mellitus}

One hundred and seventy-seven (49.4\%) of men with T2DM had diabetes for a period of 0-5years, 91 (25.4\%)
Table 1. Socio-demographic characteristics of the men with type 2 diabetes mellitus and controls

\begin{tabular}{|c|c|c|c|}
\hline Characteristics & T2DM men & Controls & P values \\
\hline Age $($ mean $\pm S D)$ & $46.34 \pm 5.66$ & $44.09 \pm 12.39$ & 0.570 \\
\hline Marital status & & & $<0.001$ \\
\hline Married & 354 (98.9\%) & $143(79.9 \%)$ & \\
\hline Single & $3(0.8 \%)$ & 35 (19.5\%) & \\
\hline Divorced & $0(0 \%)$ & $1(0.6 \%)$ & \\
\hline Widowed & $1(0.3 \%)$ & $0(0 \%)$ & \\
\hline Total & $358(100 \%)$ & $179(100 \%)$ & \\
\hline Occupation & & & $<0.001$ \\
\hline Business & $106(29.7 \%)$ & $11(6.2 \%)$ & \\
\hline Civil servant & $116(32.4 \%)$ & $134(74.8 \%)$ & \\
\hline Farming & $63(17.5 \%)$ & $22(12.2 \%)$ & \\
\hline Students & $2(0.6 \%)$ & $6(3.5 \%)$ & \\
\hline Unemployed & $2(0.6 \%)$ & $2(1.1 \%)$ & \\
\hline Others* & $69(19.2 \%)$ & $4(2.2 \%)$ & \\
\hline Total & $358(100 \%)$ & $179(100 \%)$ & \\
\hline \multicolumn{2}{|c|}{ Highest educational level } & & $<0.001$ \\
\hline Primary & $65(18.2 \%)$ & $34(19.0 \%)$ & \\
\hline Secondary & $53(14.8 \%)$ & $98(54.7 \%)$ & \\
\hline Tertiary & $143(39.9 \%)$ & $27(15.1 \%)$ & \\
\hline No formal education & $97(27.1 \%)$ & $20(11.2 \%)$ & \\
\hline Total & $358(100 \%)$ & $179(100 \%)$ & \\
\hline
\end{tabular}

* Retirees, clergy

ones for a period ranging between $6-10$ years, while $15.4 \%, 3.6 \%$ and $6.2 \%$ of men had diabetes for $11-15$, 16-20 and more than 20 years respectively. Among men with T2DM, the majority took a combination of metformin and glimepiride therapy, as shown in Figure 1. The prevalence of hypertension among men with T2DM was $75 \%$, and the prevalence of obesity in type 2 diabetic men using body mass index (BMI) and waist circumference was $14.5 \%$ and $43.6 \%$ respectively. However, among the controls, $10.1 \%$ had abdominal obesity. Among men with T2DM, 39.1\% achieved target fasting plasma glucose, $46.9 \%$ had poor glycaemic control, and $14 \%$ had tight glycaemic control. Meanwhile, $85.8 \%$ of men with T2DM did not achieve target glycated haemoglobin.

\section{Prevalence of hypogonadism}

The prevalence of hypogonadism in men with T2DM was $80.4 \%$ while in the controls, the prevalence was $10 \%$. Hypogonadism was defined as serum total testosterone $<8 \mathrm{nmol} / \mathrm{L}$ with or without symptoms or serum total testosterone $8-12 \mathrm{nmol} / \mathrm{L}$ with the presence of symptoms. Among the hypogonadal type 2 diabetic men, $38.5 \%$ had severe hypogonadism (total testosterone levels less than $8 \mathrm{nmol} / \mathrm{L}$ ) and $41.9 \%$ had mild hypogonadism (total testosterone levels between 8-12 nmol/L). The 


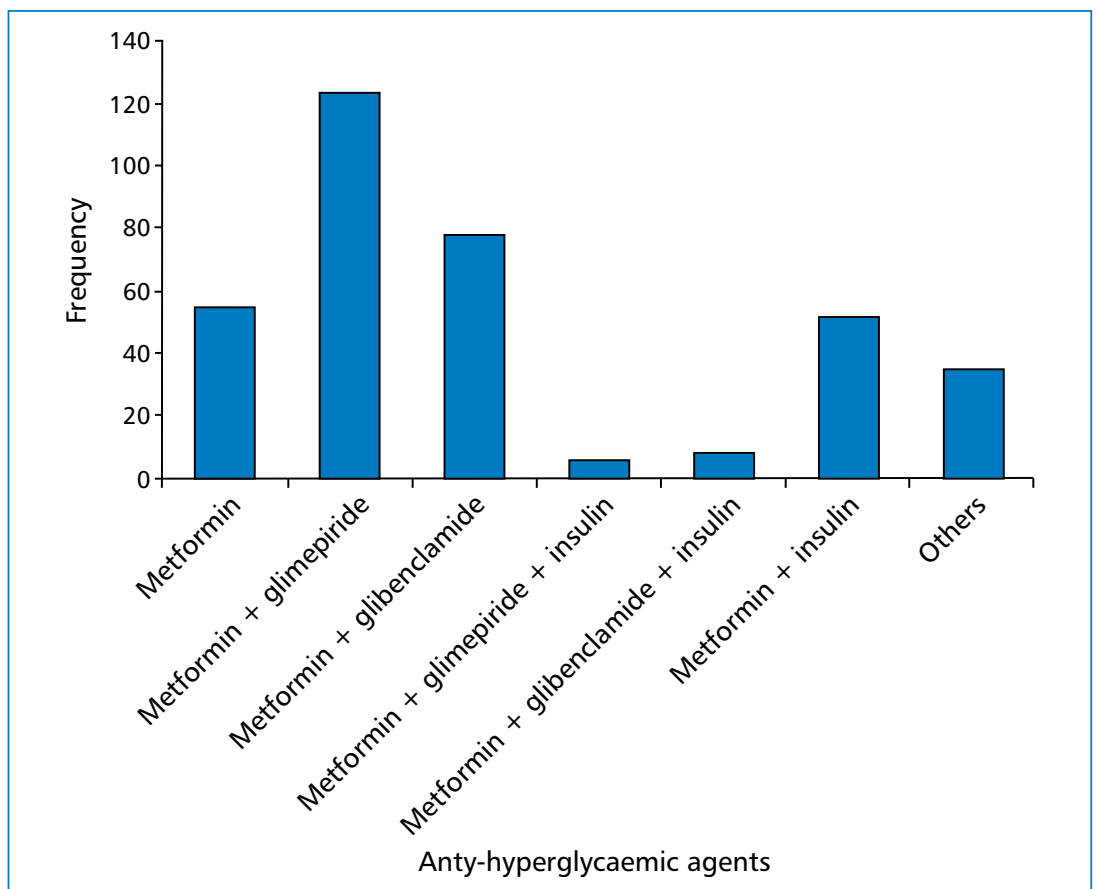

Figure 1. Anti-hyperglycaemic agents used by men with type 2 diabetes mellitus

Table 2. Mean $( \pm S D)$ clinical and biochemical profile of the men with type 2 diabetes mellitus and controls

\begin{tabular}{lccc}
\hline & $\begin{array}{c}\text { Type 2 diabetic men } \\
\text { Mean } \pm \text { SD }\end{array}$ & $\begin{array}{c}\text { Controls } \\
\text { Mean } \pm \text { SD }\end{array}$ & $\begin{array}{c}\text { Significance } \\
\text { (P-values) }\end{array}$ \\
\hline Weight [kg] & $72.84 \pm 14.13$ & $67.79 \pm 12.23$ & $<0.001$ \\
BMI [kg/m²] & $25.26 \pm 4.45$ & $24.31 \pm 3.79$ & 0.010 \\
WC [cm] & $92.40 \pm 11.96$ & $79.49 \pm 9.84$ & $<0.001$ \\
FPG [mmol/L] & $8.30 \pm 4.77$ & $4.43 \pm 1.79$ & $<0.001$ \\
HbA 1 [\% $[\%]$ & $9.13 \pm 2.12$ & $5.07 \pm 0.74$ & $<0.001$ \\
Total testosterone [nmol/L] & $8.79 \pm 3.35$ & $15.41 \pm 3.79$ & $<0.001$ \\
LH [IU/L] [0-hours] & $9.62 \pm 6.82$ & $8.24 \pm 5.91$ & 0.022 \\
FSH [IU/L] [0-hours] & $8.50 \pm 8.17$ & $5.17 \pm 3.89$ & $<0.001$ \\
\hline
\end{tabular}

$\mathrm{P}<0.05$ is statistically significant. BMI — body mass index; FSH — follicle-stimulating hormone; FPG — fasting plasma glucose; $\mathrm{HbA}{ }_{1 \mathrm{c}}-$ glycated haemoglobin; LH - luteinizing hormone; WC - waist circumference

mean $( \pm \mathrm{SD})$ total testosterone levels of men with T2DM and controls were $8.79 \pm 3.35 \mathrm{nmol} / \mathrm{L}$ and $15.41 \pm 3.79$ $\mathrm{nmol} / \mathrm{L}$, respectively. The mean total testosterone level in men with T2DM was statistically significantly lower compared to the controls $(p<0.001)$ as shown in Table 2 .

Comparison of clinical features of hypogonadism using ADAM questionnaire in men with type 2 diabetes mellitus and controls

The most commonly documented features of hypogonadism (low testosterone) among men with T2DM were erectile dysfunction, loss of libido, decreased in strength/endurance and lack of energy. Majority of the eugonadal controls had no symptoms of androgen deficiency syndrome. Decreased strength/endurance was the most statistically significant feature of androgen deficiency syndrome among men with T2DM with hypogonadism compared with the eugonadal men ( $p=0.033$, Table 3 ).

\section{Gonadotropins of men with type 2 diabetes mellitus}

The mean $( \pm S D)$ luteinizing hormone (LH) levels of the men with T2DM and controls were $9.62 \pm 6.82 \mathrm{IU} / \mathrm{L}$ 
Table 3. Comparison of clinical features of hypogonadism (using ADAM Questionnaire) in men with type 2 diabetes mellitus and controls

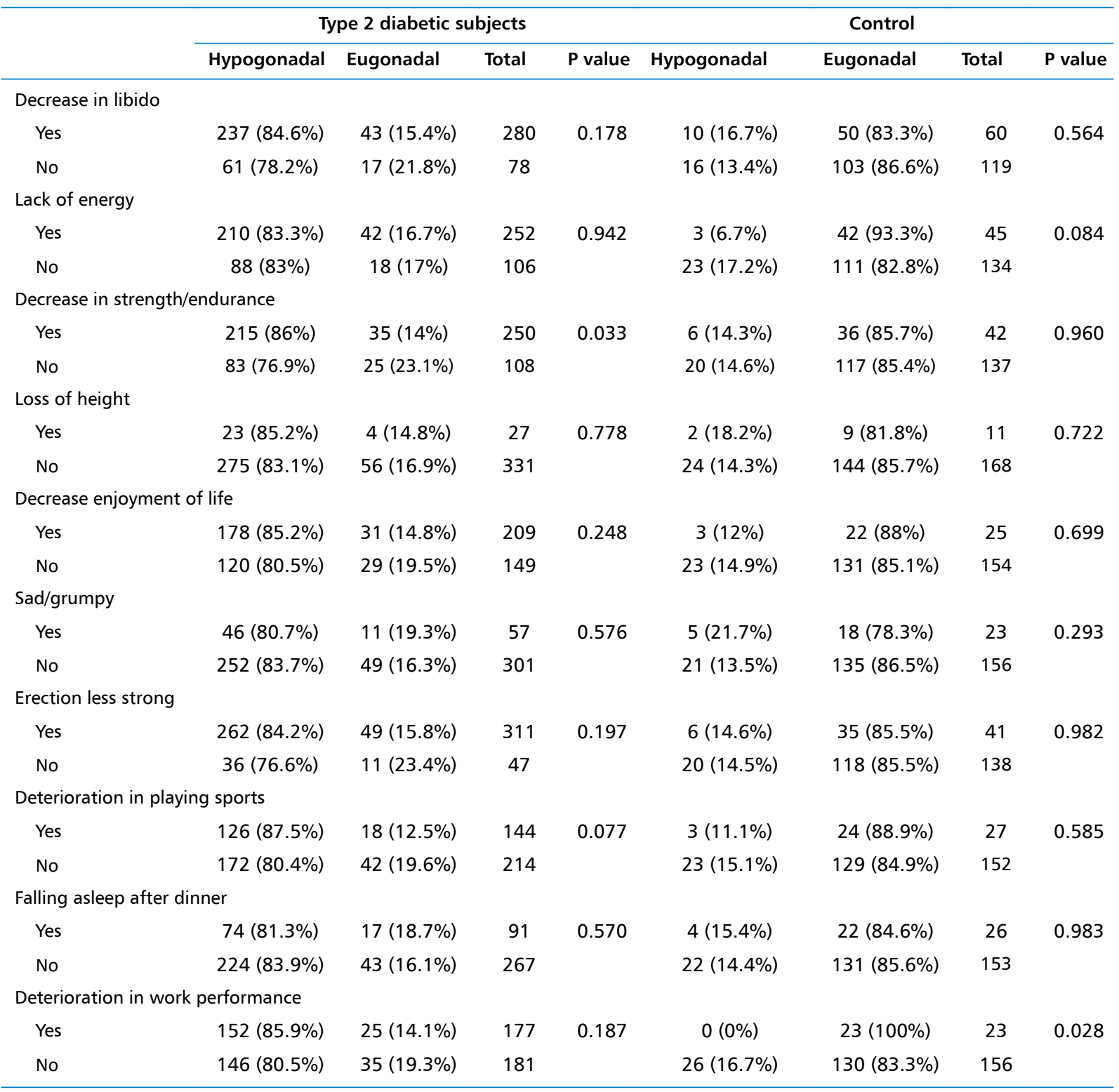

and $8.24 \pm 5.91 \mathrm{IU} / \mathrm{L}$, respectively. The mean serum $\mathrm{LH}$ level was statistically significantly higher in men with T2DM compared to the controls ( $p=0.022$, Table 2 ). Similarly, the mean $( \pm S D)$ follicle-stimulating hormone level was $8.50 \pm 8.17 \mathrm{IU} / \mathrm{L}$ for type 2 diabetic men and $5.17 \pm 3.89 \mathrm{IU} / \mathrm{L}$ for the controls. The mean FSH level was statistically significantly higher in men with T2DM compared to the controls ( $p<0.001$, Table 2 ).

Hormonal profile of men with type 2 diabetes mellitus before and after GnRH (Buserelin) stimulation test

Following GnRH stimulation test using subcutaneous buserelin in 99 men with T2DM, the mean $( \pm$ SD) LH and FSH at baseline (0 hours) were $8.38 \pm 6.10 \mathrm{IU} / \mathrm{L}$ and $8.41 \pm 7.45 \mathrm{IU} / \mathrm{L}$ respectively while the mean $( \pm S D)$ values for $\mathrm{LH}$ and FSH at 4 hours post buserelin administration were 58.58 $\pm 40.72 \mathrm{IU} / \mathrm{L}$ and $23.03 \pm 18.02 \mathrm{IU} / \mathrm{L}$ respectively. The levels of LH and FSH at 4 hours after buserelin injection were higher than the levels of $\mathrm{LH}$ and FSH at 0 hours, and these were statistically significant $(p<0.001$, Table 4). An exaggerated response was found in most of the GnRH stimulated type 2 diabetic men with hypogonadism constituting $65 \%$ and $91.2 \%$ for $\mathrm{LH}$ and $\mathrm{FSH}$, respectively (Table 4). This finding was consistent with hypergonadotropic hypogonadism. 
Table 4. The pattern of hypogonadism in men with type 2 diabetes mellitus using GnRH (Buserelin) stimulation test

\begin{tabular}{|c|c|c|c|}
\hline \multicolumn{4}{|c|}{ Mean ( \pm SD) luteinizing hormone and follicle stimulating hormone before and after GnRH stimulation } \\
\hline & Before stimulation (basal) & After stimulation & P values \\
\hline $\mathrm{LH}(\mathrm{IU} / \mathrm{L})$ & $8.38 \pm 6.10$ & $58.58 \pm 40.72$ & $<0.001$ \\
\hline FSH (IU/L) & $8.41 \pm 7.45$ & $23.03 \pm 18.02$ & $<0.001$ \\
\hline \multicolumn{4}{|c|}{ Nature of gonadotropins response to buserelin injection among GnRH stimulated type 2 diabetic men with hypogonadism } \\
\hline & Exaggerated response frequency & Normal response frequency & \\
\hline LH (IU/L) & $52(65 \%)$ & $28(35 \%)$ & \\
\hline FSH (IU/L) & 73 (91.2\%) & $7(8.8 \%)$ & \\
\hline
\end{tabular}

$\mathrm{P}<0.05$ is statistically significant. $\mathrm{FSH}$ - follicle-stimulating hormone; $\mathrm{LH}$ - luteinizing hormone

Table 5. Correlations between hormones and obesity and glycaemia in men with T2DM

\begin{tabular}{lccc}
\hline & Total testosterone & LH & FSH \\
\hline Total testosterone & & -0.064 & $-0.137^{*}$ \\
LH & -0.064 & & $0.498^{*}$ \\
FSH & $-0.137^{*}$ & $0.498^{*}$ & \\
BMI & -0.059 & 0.012 & -0.023 \\
WC & -0.081 & 0.074 & 0.022 \\
FBG & 0.017 & 0.044 & 0.009 \\
HbA1c & 0.001 & 0.012 & -0.035 \\
\hline
\end{tabular}

* Correlation is significant at $\mathrm{p}<0.05$. BMI - body mass index; FBG - fasting blood glucose; FSH - follicle-stimulating hormone; $\mathrm{HbA}_{1 \mathrm{c}}$ - glycated haemoglobin; $\mathrm{LH}$ - luteinizing hormone; WC — waist circumference

\section{Correlations between total testosterone, LH, FSH} and obesity and glycaemia in men with T2DM

There was a negative correlation between serum total testosterone and $\mathrm{FSH}, \mathrm{LH}, \mathrm{BMI}$, and WC, but only FSH reached statistical significance. Furthermore, total testosterone was not significantly correlated with fasting plasma glucose and glycated haemoglobin (Table 5).

\section{Discussion}

Several cross-sectional studies have reported a high prevalence of hypogonadism in men with T2DM [13-17]. This study demonstrated that the prevalence of hypogonadism in men with T2DM was $80.4 \%$ while in the controls, the prevalence was $10 \%$. The prevalence of hypogonadism in men with T2DM was statistically significantly higher than in the controls. Studies from Nigeria and South Africa, compared to this study, reported a lower prevalence of hypogonadism or low serum total testosterone in men with T2DM [15-17, 25]. In Nigeria, Ogbera et al. reported the prevalence of hypogonadism among men with T2DM to be $36 \%$ at General Hospital Gbagada, Lagos. In comparison, Onung et al reported a prevalence of $38.9 \%$ in Lagos and Ugwu et al. reported a prevalence of $52.5 \%$ in lle-Ife [15-17]. Paruk et al. reported the prevalence of low serum total testosterone in men with T2DM to be $35.8 \%$ [25]. Tan et al. reported a prevalence of hypogonadism among elderly diabetics to be $64 \%$; however, the effect of advancing age on testosterone levels could have been a confounding factor [28]. Similarly, some studies have reported the prevalence of hypogonadism to be $30-80 \%$ in T2DM [13, 21]. This study demonstrated a similar higher prevalence of hypogonadism among men with T2DM compared to previous studies, and this perhaps may be attributed to the disparity in the diagnostic criteria, laboratory assay methods, central obesity and poor metabolic control. Our study population was from Northern Nigeria where poverty is high compared the Southern Nigeria, from where studies have reported a lower prevalence of hypogonadism [29]. Putatively, low socioeconomic level of the study population may be negatively impacting on metabolic control due to limited health-care access and affordability to medications. Further, a high proportion of men with T2DM had obesity and poor glycaemic control which have been reported to be associated with hypogonadism [21]. In this study, $85.8 \%$ of men with T2DM did not achieve the glycated haemoglobin target, which may explain the high frequency of hypogonadism in the men with T2DM. Although in this study, there was no significant correlation between total testosterone and glycated haemoglobin as reported in another study [30], this might have been impacted by the massive number of patients who did not achieve target glycated haemoglobin. Cross-sectional studies have reported a negative correlation between total testosterone and $\mathrm{HbA}_{1 \mathrm{c}}[17,31,32]$. Also, total testosterone inversely correlated with obesity (BMI, WC), although this was not statistically significant. Several studies have reported an association between low testosterone and central obesity [33-36]. Poor glycaemic control is known to induce defective Leydig cells function and alteration 
in the hypothalamic-pituitary-testicular axis as a result of high estradiol, cytokines, advanced glycated end products and leptin that are associated with obesity and hyperglycaemia [16, 37]. Majority of the men with T2DM had mild hypogonadism with severe hypogonadism accounting for $38.5 \%$. The prevalence of severe hypogonadism in this study was comparable with the reported incidence by Asare-Anane et al. [37]. However, other cross-sectional studies reported a lower prevalence of severe or overt hypogonadism among men with T2DM $[15,17,21]$. Among the controls, the prevalence of hypogonadism was $10 \%$, which was comparable to the reports from Ghanaian, Jordanian and Italian studies [13, 37, 38].

Dissecting the social component, most of the men with T2DM in this study were married, and they accounted for $98.9 \%$. This finding was comparable with the proportion of married type 2 diabetic men in a similar study in Ethiopia [39]. With this finding and considering the high frequency of hypogonadism in this study, it is hypothesized that large numbers of men with T2DM might be at risk of strain marital relationships which could probably culminate in separation and divorce, hence, impacting negatively on diabetes care and creating a vicious cycle. This is supported by a report that hypogonadism can significantly reduce the quality of life with resultant loss of livelihood, thereby leading to the separation of couples and divorce [40].

This study found that the most reported features of low testosterone among men with T2DM with hypogonadism were erectile dysfunction, loss of libido, decreased in strength/endurance, deterioration in work performance and lack of energy. Among these features, decreased in strength/endurance was the most significant symptom of hypogonadism. However, among the non-diabetic men, deterioration in work performance showed most significance indicating that other symptoms may be nonspecific to both eugonadal and hypogonadal type 2 diabetic men. Ogbera et al. reported similar findings where erectile dysfunction, reduced libido and lack of energy were the most frequently documented symptoms of low testosterone but it was in contrast with our finding, in which lack of energy and reduced libido showed statistical significance. In this study, $84.2 \%$ of hypogonadal type 2 diabetic men reported weak erection; however, a study by Bodie et al. reported that $18.7 \%$ of men with erectile dysfunction had low testosterone levels [41]. Erectile dysfunction in men with T2DM is modulated by factors such as serum testosterone, arterial blood flow and vasodilation and centrally regulated-mechanism of sexual activity $[42,43]$.
The findings in this study showed that hypergonadotropic hypogonadism is the more common form of hypogonadism in men with T2DM using basal and $\mathrm{GnRH}$ stimulated LH and FSH. Majority of the stimulated type 2 diabetic men had exaggerated response in $\mathrm{LH}$ (65\%) and FSH (91.2\%) following buserelin injection consistent with primary hypogonadism. However, $35 \%$ and $8.8 \%$ showed a normal response in $\mathrm{LH}$ and $\mathrm{FSH}$, respectively to $\mathrm{GnRH}$ stimulation, suggesting a lower proportion of patients with T2DM may have hypogonadotropic hypogonadism. A previous study found a normal GnRH stimulation test in type 2 diabetic patients [44]. Asare-Anane et al. reported primary hypogonadism as the main type of hypogonadism in Ghanaian type 2 diabetic men using basal gonadotropins in contrast to this study [22]. Many studies which used only basal gonadotropins have shown that hypogonadotropic hypogonadism is the more frequent type hypogonadism in male patients with T2DM; however, this has some limitation, mainly when gonadotropins levels are borderline [30, 45, 46]. These study findings may be explained by the resultant effect of chronic hyperglycaemia on testicular microvasculature, which leads to alteration in Leydig cells integrity via cytokines release, thereby leading to hypogonadism. Also, insulin resistance which is a hallmark of T2DM may prevent an adequate supply of energy required for the various metabolic processes involved in testosterone synthesis and release [22].

\section{Limitation and strengths of the study}

The limitation of this study might be due to its cross-sectional nature with consecutive recruitment. The study was hospital-based and might not have given an actual reflection of hypogonadism in men with T2DM. The gold standard test for measuring total testosterone is mass spectrometry which was not done due to lack of availability in Nigeria.

\section{Conclusion}

Hypogonadism was more common in men with T2DM compared to non-diabetic men, with mild hypogonadism accounting for most cases. Hypergonadotropic hypogonadism is the more frequent type of hypogonadism in Nigerian men with T2DM both at basal and GnRH stimulated states. The most reported symptoms of low testosterone in type 2 diabetic men with hypogonadism are erectile dysfunction, loss of libido, decreased in strength/endurance, deterioration in work performance and lack of energy but decreased strength/ endurance appears to be most important. Prospective research is recommended to dissect the 
causal relationship between T2DM and hypogonadism, both locally and internationally.

\section{Conflict of interest None declared.}

\section{REFERENCES}

1. Guariguata L, Linnenkamp U, Beagley J, et al. The IDF Diabetes Atlas methodology for estimating global prevalence of hyperglycaemia in pregnancy. Diabetes Res Clin Pract. 2014; 103(2): 186-196, doi: 10.1016/j.diabres.2013.11.004, indexed in Pubmed: 24300016.

2. Mbanya J, Motala $A$, Sobngwi $E$, et al. Diabetes in sub-Saharan Africa. The Lancet. 2010; 375(9733): 2254-2266, doi: 10.1016/ s0140-6736(10)60550-8.

3. Sobngwi E, Mauvais-Jarvis F, Vexiau P, et al. Diabetes in Africans. Part 1: epidemiology and clinical specificities. Diabetes Metab. 2001; 27(6): 628-634, indexed in Pubmed: 11852370.

4. Akinkugbe OIA, Johnson T. Non-communicable diseases in Nigeria. The final report of national survey. Lagos, Federal Ministry of Health - National Expert Committee on Non-Communicable Diseases. 1997: 12-41.

5. Nyenwe EA, Odia OJ, Ihekwaba AE, et al. Type 2 diabetes in adult Nigerians: a study of its prevalence and risk factors in Port Harcourt, Nigeria. Diabetes Res Clin Pract. 2003; 62(3): 177-185, doi: 10.1016/j.diabres.2003.07.002, indexed in Pubmed: 14625132.

6. Oputa R. National diabetes screening programmes. Diabetes International. 2009; 17: 9-11.

7. Dhatariya K, Nagi D, Jones TH. ABCD position statement on the management of hypogonadal males with type 2 diabetes. Practical Diabetes International. 2010; 27(9): 408-412, doi: 10.1002/ pdi.1535.

8. Nieschlag E, Behre HM, Bouchard P, et al. Testosterone replacement therapy: current trends and future directions. Hum Reprod Update. 2004; 10(5): 409-419, doi: 10.1093/humupd/dmh035, indexed in Pubmed: 15297434.

9. Fakih M. Prevention, diagnosis, and management of osteoporosisrelated fracture. J Am Osteopath Assoc. 2009; 109(3): 191-193, indexed in Pubmed: 19336772.

10. Kapoor D, Malkin CJ, Channer KS, et al. Androgens, insulin resistance and vascular disease in men. Clin Endocrinol (Oxf). 2005; 63(3): 239-250, doi: 10.1111/j.1365-2265.2005.02299.x, indexed in Pubmed: 16117808.

11. Traish AM, Saad F, Guay A. The dark side of testosterone deficiency: II. Type 2 diabetes and insulin resistance. J Androl. 2009; 30(1): 23-32, doi: 10.2164/jandrol.108.005751, indexed in Pubmed: 18772488

12. Vikan T, Schirmer $H$, Njølstad I, et al. Low testosterone and sex hormone-binding globulin levels and high estradiol levels are independent predictors of type 2 diabetes in men. Eur J Endocrinol. 2010; 162(4): 747-754, doi: 10.1530/EJE-09-0943, indexed in Pubmed: 20061333

13. Corona G, Mannucci E, Petrone L, et al. Association of hypogonadism and type II diabetes in men attending an outpatient erectile dysfunction clinic. Int J Impot Res. 2006; 18(2): 190-197, doi: 10.1038/sj.ijir.3901391, indexed in Pubmed: 16136189.

14. Grossmann M, Thomas MC, Panagiotopoulos S, et al. Low testosterone levels are common and associated with insulin resistance in men with diabetes. J Clin Endocrinol Metab. 2008; 93(5): 1834-1840, doi: 10.1210/jc.2007-2177, indexed in Pubmed: 18319314.

15. Ogbera OA, Sonny C, Olufemi F, et al. Hypogonadism and subnormal total testosterone levels in men with type 2 diabetes mellitus. J Coll Physicians Surg Pak. 2011; 21(9): 517-521, doi: 09.2011/ JCPSP.517521, indexed in Pubmed: 21914405.
16. Onung SI, Young EE, Ugwu TE, et al. Hypogonadism in Nigerian men with type 2 diabetes mellitus. International Journal of Diabetes in Developing Countries. 2016; 37(3): 254-261, doi: 10.1007/s13410-016-0481-x.

17. Ugwu TE, Ikem RT, Kolawole BA, et al. Clinicopathologic assessment of hypogonadism in men with type 2 diabetes mellitus. Indian J Endocrinol Metab. 2016; 20(5): 667-673, doi: 10.4103/2230-8210.190554, indexed in Pubmed: 27730078.

18. Kemp T, Rheeder P. The prevalence and association of low testosterone levels in a South African male, diabetic, urban population. Journal of Endocrinology, Metabolism and Diabetes of South Africa. 2015; 20(2): 92-97, doi: 10.1080/16089677.2015.1056478.

19. Hackett G, Cole N, Deshpande A, et al. Biochemical hypogonadism in men with type 2 diabetes in primary care practice. The British Journal of Diabetes \& Vascular Disease. 2009; 9(5): 226-231, doi: $10.1177 / 1474651409342635$

20. Ganesh HK, Vijaya Sarathi HA, George J, et al. Prevalence of hypogonadism in patients with type 2 diabetes mellitus in an Asian Indian study group. Endocr Pract. 2009; 15(6): 513-520, doi: 10.4158/EP09035.ORR, indexed in Pubmed: 19454386.

21. Kapoor D, Aldred H, Clark S, et al. Clinical and biochemical assessment of hypogonadism in men with type 2 diabetes: correlations with bioavailable testosterone and visceral adiposity. Diabetes Care. 2007; 30(4): 911-917, doi: 10.2337/dc06-1426, indexed in Pubmed: 17392552.

22. Asare-Anane H, Ofori E, Yeboah F, et al. Primary hypogonadism in Ghanaian men with type 2 diabetes mellitus. IJSTR. 2013; 2(5): 310-5.

23. American Association of Clinical Endocrinologists Medical Guidelines for Clinical Practice for the Evaluation and Treatment of Hypogonadism in Adult Male Patients-2002 Update. Endocrine Practice. 2002; 8(6): 439-456, doi: 10.4158/ep.8.6.439.

24. Wilson DA, Hofman PL, Miles HL, et al. Evaluation of the buserelin stimulation test in diagnosing gonadotropin deficiency in males with delayed puberty. J Pediatr. 2006; 148(1): 89-94, doi: 10.1016/j.jpeds.2005.08.045, indexed in Pubmed: 16423605.

25. Paruk IM, Pirie FJ, Nkwanyana NM, et al. Prevalence of low serum testosterone levels among men with type 2 diabetes mellitus attending two outpatient diabetes clinics in KwaZulu-Natal Province, South Africa. S Afr Med J. 2019; 109(12): 963-970, doi: 10.7196/SAMJ.2019.v109i12.013893, indexed in Pubmed: 31865960.

26. Morley JE, Charlton E, Patrick $P$, et al. Validation of a screening questionnaire for androgen deficiency in aging males. Metabolism. 2000; 49(9): 1239-1242, doi: 10.1053/meta.2000.8625, indexed in Pubmed: 11016912

27. Nieschlag E, Swerdloff R, Behre HM, et al. Investigation, treatment and monitoring of late-onset hypogonadism in males: ISA, ISSAM, and EAU recommendations. Int J Androl. 2005; 28(3): 125-127, doi: 10.1111/j.1365-2605.2005.00553.x, indexed in Pubmed: 15910536.

28. Tan RS, Pu SJ. Impact of obesity on hypogonadism in the andropause. Int J Androl. 2002; 25(4): 195-201, doi: 10.1046/j.13652605.2002.00356.x indexed in Pubmed: 12121568.

29. Dapel Z. Poverty in Nigeria: Understanding and bridging the divide between north and south. Centre for Global Development. 2018.

30. Dhindsa S, Prabhakar S, Sethi M, et al. Frequent occurrence of hypogonadotropic hypogonadism in type 2 diabetes. J Clin Endocrinol Metab. 2004; 89(11): 5462-5468, doi: 10.1210/ jc. 2004-0804, indexed in Pubmed: 15531498.

31. Rabijewski M, Papierska L, Zgliczyński W, et al. The incidence of hypogonadotropic hypogonadism in type 2 diabetic men in Polish population. Biomed Res Int. 2013; 2013: 767496, doi: 10.1155/2013/767496, indexed in Pubmed: 24222915.

32. Kim JS, Kim BS, Jeon JaY, et al. Testosterone deficiency associated with poor glycemic control in korean male diabetics. Endocrinol Metab (Seoul). 2014; 29(3): 300-306, doi: 10.3803/ EnM.2014.29.3.300, indexed in Pubmed: 25309788. 
33. Haffner SM, Mykkänen L, Valdez RA, et al. Relationship of sex hormones to lipids and lipoproteins in nondiabetic men. J Clin Endocrinol Metab. 1993; 77(6): 1610-1615, doi: 10.1210/ jcem.77.6.8263149, indexed in Pubmed: 8263149.

34. Madhu SV, Aslam M, Aiman A, et al. Prevalence of hypogonadism in male Type 2 diabetes mellitus patients with and without coronary artery disease. Indian J Endocrinol Metab. 2017; 21(1): 31-37, doi: 10.4103/2230-8210.195999, indexed in Pubmed: 28217495.

35. Phillips GB. Relationship between serum sex hormones and the glucose-insulin-lipid defect in men with obesity. Metabolism. 1993; 42(1): 116-120, doi: 10.1016/0026-0495(93)90181-m, indexed in Pubmed: 8446038.

36. Seidell JC, Björntorp P, Sjöström L, et al. Visceral fat accumulation in men is positively associated with insulin, glucose, and C-peptide levels, but negatively with testosterone levels. Metabolism. 1990; 39(9): 897-901, doi: 10.1016/0026-0495(90)90297-p, indexed in Pubmed: 2202881.

37. Asare-Anane H, Ofori E, Agyemang $\mathrm{Y}$, et al. Obesity and testosterone levels in Ghanaian men with type 2 diabetes. Clin Diabetes. 2014; 32(2): 61-65, doi: 10.2337/diaclin.32.2.61, indexed in Pubmed: 26130863.

38. Al Hayek AA, Khawaja NM, Khader YS, et al. The prevalence of Hypogonadism among diabetic and non-diabetic men in Jordan. J Diabetes Complications. 2014; 28(2): 135-140, doi: 10.1016/j. jdiacomp.2013.11.004, indexed in Pubmed: 24388552.

39. Teka S, Kinde S, Dedefo G, et al. Hypogonadism and associated risk factors in male patients with type 2 diabetes mellitus attending the diabetic clinic of Tikur Anbessa Specialized Teaching Hospital, Addis Ababa, Ethiopia. Journal of Endocrinology, Me- tabolism and Diabetes of South Africa. 2018; 24(1): 16-22, doi: 10.1080/16089677.2018.1541668.

40. Kumar P, Kumar N, Thakur DS, et al. Male hypogonadism: Symptoms and treatment. J Adv Pharm Technol Res. 2010; 1(3): 297-301, doi: 10.4103/0110-5558.72420, indexed in Pubmed: 22247861.

41. Bodie J, Lewis J, Schow D, et al. Laboratory evaluations of erectile dysfunction: an evidence based approach. J Urol. 2003; 169(6): 2262-2264, doi: 10.1097/01.ju.0000063940.19080.58, indexed in Pubmed: 12771765.

42. Traish AM, Goldstein I, Kim NN. Testosterone and erectile function: from basic research to a new clinical paradigm for managing men with androgen insufficiency and erectile dysfunction. Eur Urol. 2007; 52(1): 54-70, doi: 10.1016/j.eururo.2007.02.034, indexed in Pubmed: 17329016.

43. Galloway M. Testosterone deficiency syndrome: a common factor in type 2 diabetes and erectile dysfunction patients. Prac Diab Int. 2008; 25: 3-10.

44. Tripathy D, Dhindsa S, Garg R, et al. Hypogonadotropic hypogonadism in erectile dysfunction associated with type 2 diabetes mellitus: a common defect? Metab Syndr Relat Disord. 2003; 1(1): 75-80, doi: 10.1089/154041903321648270, indexed in Pubmed: 18370627.

45. Alhayek A, Khader Y, Jafal S, et al. Hypogonadism among Jordanian men with type 2 diabetes: Prevalence and associated factor. International Journal of Diabetes Mellitus. 2015; 3(1): 31-36, doi: 10.1016/j.ijdm.2011.01.003.

46. Rabijewski M, Papierska L, Zgliczyński W, et al. The incidence of hypogonadotropic hypogonadism in type 2 diabetic men in Polish population. Biomed Res Int. 2013; 2013: 767496, doi: 10.1155/2013/767496, indexed in Pubmed: 24222915. 